\title{
Sebaran Mikroba Tanah pada Berbagai Jenis Penggunaan Lahan Di Kawasan Bandung Utara
}

\author{
Muhammad Amir Solihin dan Betty Natalie Fitriatin \\ Staff Pengajar Departemen Ilmu Tanah dan Sumberdaya Lahan Fakultas Pertanian \\ Universitas Padjadjaran \\ Jl. Raya Bandung Sumedang Km 21 Jatinangor \\ Korespondensi: amir_solihin@unpad.ac.id
}

\begin{abstract}
North of Bandung have regional multifunction. Thereby, land resources management based on existing land characteristic is important. One of important land biophysic potential is soil microorganism. Study location area is 14.492 Hectare. The research methode is survey research which characterization analysis using remote sensing interpretation, geographical information system analysis, and soil microorganism population analysis. Research result shows variation of biodiversity potency of several soil microorganism type in study location. High potency of soil microorganism in 5.020,23 Hectare $(34,64 \%)$ areas, medium potency in $2.309,86$ Hectare $(15,94 \%)$ areas and low potency in 2.362,76 Hectare (16,30\%) areas. Those biophysic potency important to sustainable agriculture development based on organic farming in the North of Bandung Area.
\end{abstract}

Keywords: humic acid, role of humic acid

\section{PENDAHULUAN}

Kawasan Bandung Utara (KBU) merupakan wilayah dengan perkembangan sangat pesat dan dinamis. Pertentangan antara fungsi KBU dan kepentingan pembangunan seringkali menyebabkan aspek lingkungan diabaikan. KBU mempunyai fungsi fisik (ekologis), sosial dan ekonomi. Namun dilain pihak pembangunan yang ditunjang oleh kekuatan perkembangan ekonomi wilayah perkotaan khususnya Kota Bandung dan Cimahi berdampak terhadap penyebaran pembangunan ke wilayah sekitarnya pada akhirnya akan menyebabkan terjadinya perubahan guna lahan dan biofisik lahan KBU.

Telah banyak dampak negatif yang timbul akibat pola pembangunan yang demikian. Untuk itu perlu suatu upaya agar pengelolaan sumberdaya lahan dapat bersifat optimal lestari dan berkelanjutan. Kondisi eksisting KBU merupakan salah satu sentra produksi pertanian, dan perkebunan. Untuk menunjang pemanfaatannya yang optimal, perlu diketahui potensi biofisik lahan (Food and Agriculture Organization, 1976). Potensi biofisik lahan ini dapat diketahui melalui karakteristik lahannya. Karakterisasi biofisik lahan dapat dilakukan melalui proses inventarisasi sumberdaya lahan dan penilaian kondisi lahan (Sitorus, 2004).

Nilai lahan tersebut berkaitan erat dengan kondisi kesehatan tanah atau kesuburannya. Ciri-ciri tanah yang sehat adalah : (1) populasi organismenya beragam dan aktif (2) memiliki dalam jumlah tinggi residu yang relatip segar sebagai sumber makananorganisme dan (3) memiliki dalam jumlah tinggi bahan organik yang terhumifikasi untuk mengikat air dan muatan negatip untuk pertukaran kation (Magdoff, 2001). Salah satu karakteristik biofisik lahan yang perlu diketahui guna menunjang pertanian yang berkelanjutan adalah mikroba tanah.

Organisme tanah cukup baik sebagai bioindikator tanah karena memiliki respon yang sensitip terhadap praktek pengelolaan lahan dan iklim, berkorelasi baik terhadap sifat tanah yang menguntungkan dan fungsi ekologis dapat menggambarkan rantai sebabakibat yang menghubungkan keputusan pengelolaan lahan terhadap produktivitas. 
Tetapi pengukuran organisme tanah memerlukan banyak kriteria supaya dapat digunakan sepenuhnya sebagai indikator pengelolaan lahan yang sesuai, termasuk populasinya, keragaman,struktur jaringan dan stabilitas komunitas.

Karakterisasi biologi dapat diduga melalui karakteteristik tanah lainnya. Beberapa faktor yang mempengaruhi enzim fosfatase dan fitase menurut Saparatka (2003) antara lain : kelembaban tanah, suhu, aerasi dan struktur, $\mathrm{pH}$, kandungan koloid anorganik dan koloid organik. Adanya vegetasi juga mempengaruhi aktivitas enzim fosfatase dan fitase. Penelitian Fitriatin (2007), melaporkan bahwa populasi bakteri pelarut fosfat pada tanah Ultisols lebih banyak di bandingkan pada tanah Andisols. Hal ini menunjukkan bahwa karakteristik tanah yang berbeda mempengaruhi populasi mikroba tanah. Untuk itu, Rao (1994) merumuskan perbedaan jumlah populasi mikroba tanah ke dalam beberapa kelas. Hal ini dapat menjadi dasar penilaian potensi dalam menunjang pertanian yang berkelanjutan.

Keragaman biologis tanah juga dapat dipengaruhi oleh jenis penggunaan lahan. Coleman et al. (2005) menyatakan bahwa biodiversitas tinggi dari mikroba terdapat pada tanah-tanah dengan vegetasi yang berbeda. Hasil penelitian Fitriatin (2006) menunjukkan bahwa aktivitas enzim fosfatase pada rhizosfir lebih besar dibadingkan di daerah nonrhizosfir. Hal ini menunjukkan adanya aktivitas mikroorganisme di daerah rhizosfir ini lebih banyak dan memberikan kontribusi yang positif terhadap tanaman sebagai faktor-faktor dominan biologi tanah.

Identifikasi keragaman biodiversitas sebagai landasan penilaian aspek kesehatan tanah dilakukan melalui inventarisasi sumberdaya lahan. Untuk mengoptimalkan kajian dan waktu yang lebih cepat dan aktual digunakan Sistem Informasi Geografis (SIG) dan penginderaan jauh (remote sending). Pemanfaatan teknologi ini sebagai upaya untuk memperoleh data aktual secara cepat dan akurat. Pengelolaan data kebumian dengan SIG dan RS mempunyai keunggulan dalam kegiatan inventarisasi biofisik lahan dibandingkan dengan tanpa menggunakan teknologi tersebut. Aronof (1991) mengungkapkan bahwa SIG mempunyai keuntungan dalam kemampuan mengelola data dalam jumlah yang besar dan kompleks. Sedangkan remote sensing menunjang inventarisasi data kebumian dalam berbagai aspek dan lebih aktual. Kemampuan tersebut, menunjang upaya karakterisasi biofisik lahan KBU dengan kondisi lahannya yang bervariasi.

Karakteristik sumberdaya lahan dapat diidentifikasi baik secara langsung maupun tidak langsung dengan perangkat teknologi remote sensing dan sistem informasi geografis. Namun demikian, untuk memperoleh akurasi data hasil maka interpretasi dikombinasikan dengan pendekatan fisiografis survei pemetaan lahan. Hasil survey dapat menghasilkan karakteristik sumber-daya lahan dan potensinya yang sesuai kondisi aktual lokasi studi.

\section{METODE PENELITIAN}

Kegiatan pemetaan penggunaan lahan dilakukan melalui interpretasi citra satelit yang dikelola melalui perangkat teknologi remote sensing dan SIG. Klasifikasi penggunaan lahan menggunakan data Citra Satelit Landsat TM 2008 Path/Row 122/065. Selain itu penelitian ini menggunakan juga Peta Topografi skala 1:50 000, Peta Rupa Bumi skala 1:50 000, Peta Tanah skala 1:50 000 dan data iklim maupun tanah di lokasi studi. Untuk pengolahan data digunakan Software ArcGis, SPSS17, Ermapper.

Interperetasi Citra untuk menentukan jenis penggunaan lahan aktual digunakan metoda Maximum Likelihood. Karakterisasi lahan dan pengambilan contoh tanah dilakukan melalui kegiatan survey tanah dengan pendekatan fisiografis, dimana karakteristik lahan lokasi studi dikelompokan berdasarkan satuan lahan. Kegiatan survey lapangan (groundchek) ini dilakukan pengambilan data koordinat menggunakan GPS, dan data kemiringan lahan menggunakan 
klinometer. Pengambilan contoh tanah dilakukan dengan menggunakan ring sampler.

Analisis mikroba tanah dilakukan di Laboratorium Biologi Tanah, Fakultas Pertanian UNPAD. analisis populasi mikroba dengan menggunakan metode plat pengenceran (dilution plate methode). Analisis data sebaran mikroba dilakukan secara deskriptif. Tahapan penelitian dapat dilihat pada Gambar 1.

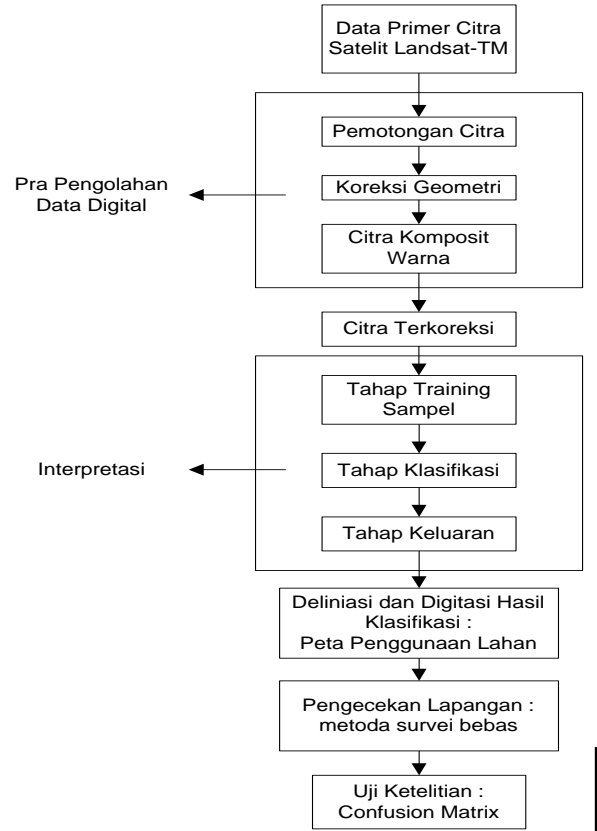

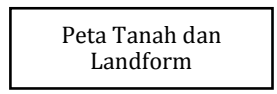
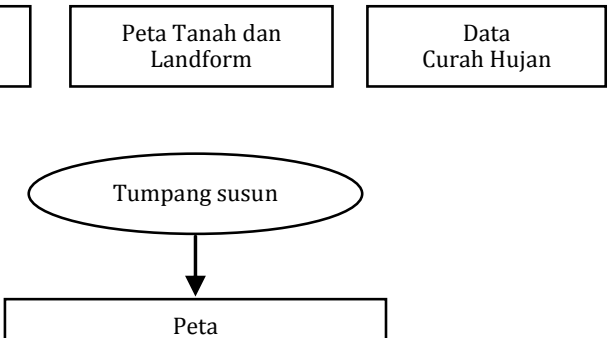

Satuan Satuan Lahan

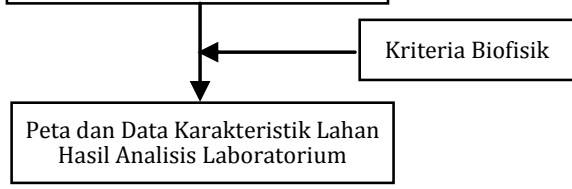

Analisis Potensi dan

Peta Potensi Biofisik Lahan (Supervised Classification)

Gambar 1 Diagram tahapan penelitian

\section{HASIL DAN PEMBAHASAN}

\subsection{Gambaran Lokasi studi}

Lokasi studi mencakup wilayah di Kecamatan Parongpong dan Lembang Kabupaten Bandung Barat. Ketinggian lokasi studi antara 750 - $2000 \mathrm{~m}$ dpl dengan luas 14.492 Ha. Bentuk wilayah berbukit dan bergunung dengan didomiasi kemiringan terjal hingga sangat terjal. Curah hujan ratarata $2130 \mathrm{~mm} /$ tahun. Di lokasi penelitian dapat dibedakan menjadi 2 (dua) ordo tanah yaitu: Andosols dan Inceptisols.

Hasil analisis citra menunjukkan tanaman semusim mendominasi penggunaan lahan di lokasi studi yaitu 44,96\% dari luas wilayah atau seluas 6.515,53 Ha. Satuan lahan yang terbentuk sebanyak 29 satuan lahan (Gambar 2).
Karakteristik biologi tanah yang dianalisis pada penelitian ini sesuai dengan hasil studi literatur. Karakteristik biologi tanah yang berperan dalam pertanian dan kesuburan tanah meliputi makro fauna dan mikroba tanah. Mikroba tanah berperan penting dalam meningkatkan kesuburan tanah pertanian karena perannya dalam perbaikan sifat fisik dan kimia tanah. Pada penelitian ini diidentifikasi karakteristik beberapa jenis mikroba tanah yang mempunyai peran terhadap kesuburan tanah. Karakteristik yang diteliti meliputi identifikasi populasi jamur, actinomycetes, azotobacter, bakteri pelarut forfat, dan bakteri tanah. Berdasarkan hasil analisis, lokasi studi memiliki keragaman populasi jamur, actinomycetes, azotobacter, bakteri pelarut fosfat maupun bakteri tanah. 


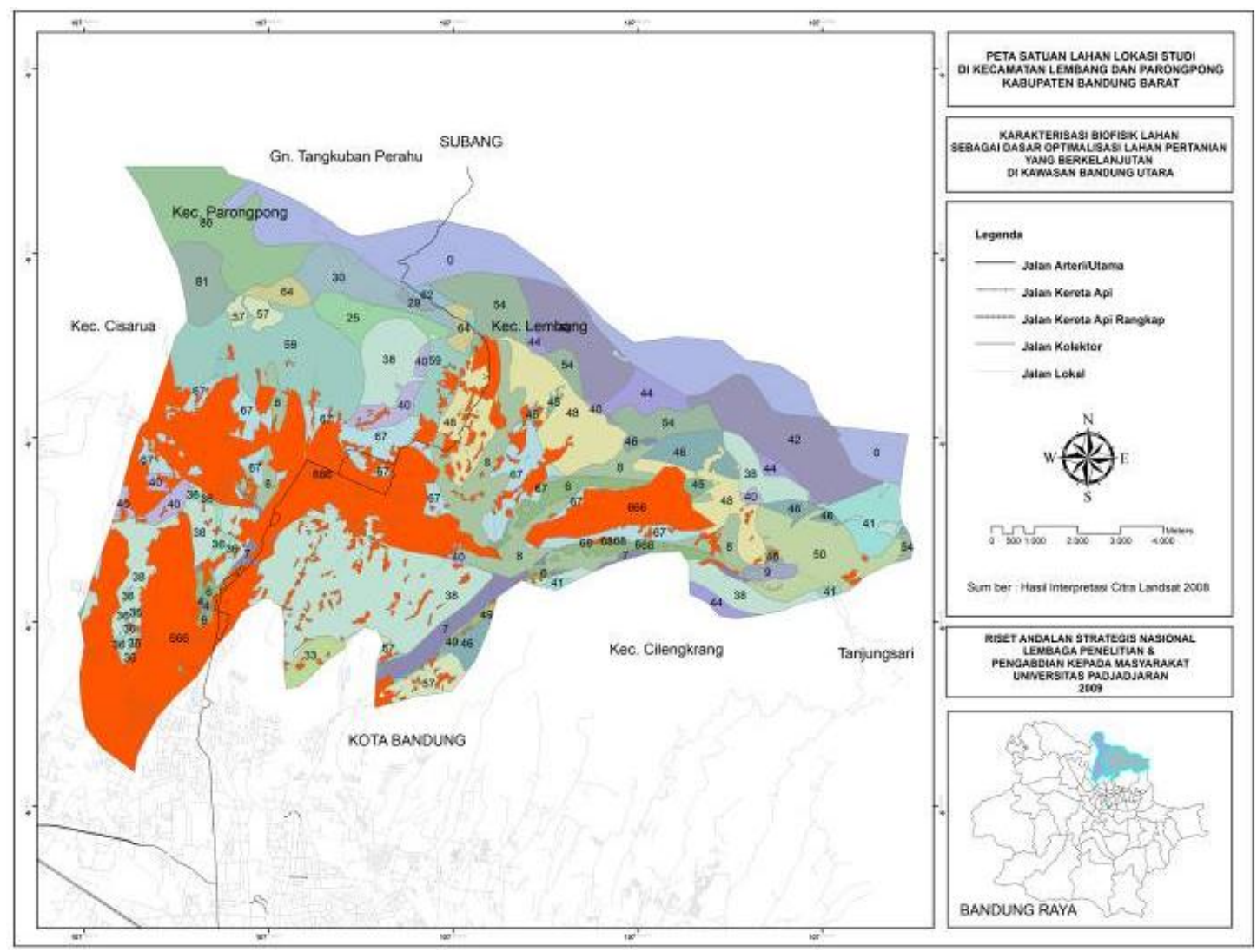

Gambar 2 Satuan lahan di lokasi studi

\subsection{Biodiversitas Mikroba Tanah Pada Berbagai Penggunaan Lahan}

Hasil penelitian menunjukkan bahwa secara umum vegetasi mempengaruhi biodiversitas mikroba di dalam tanah. Hal ini dapat dilihat dari Gambar 3. Keragaman ini dapat dilihat dari perubahan dinamika populasi mikroba berdasarkan perbedaan vegetasi. Secara umum pertanian lahan kering memiliki persentase populasi mikroba tanah yang paling tinggi dibandingkan dengan vegetasi lainnya (Tabel 1). Hal ini diduga karena vegetasi pertanian di lahan kering ini memiliki keragaman vegetasi yang tinggi yaitu sistem pertanian tumpang sari dan palawija.

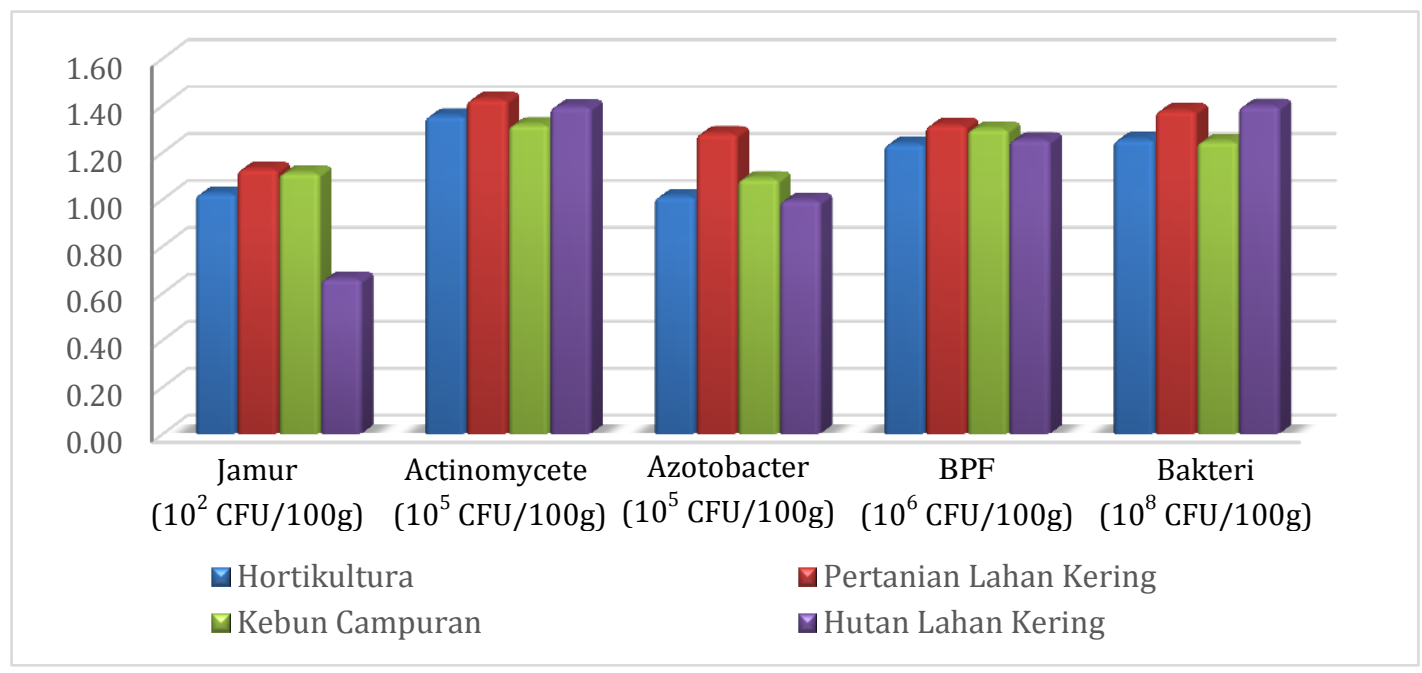

Gambar 3 Populasi mikroba tanah pada beberapa tipe penggunaan lahan 
Tabel 1 Jumlah populasi masing-masing jenis mikroba pada berbagai jenis penggunaan lahan

\begin{tabular}{lccccc}
\hline $\begin{array}{c}\text { Jenis } \\
\text { Penggunaan Lahan }\end{array}$ & $\begin{array}{c}\text { Jamur }\left(10^{2}\right. \\
\text { CFU/100g })\end{array}$ & $\begin{array}{c}\text { Actinomycetes } \\
\left(10^{5} \text { CFU/100g }\right)\end{array}$ & $\begin{array}{c}\text { Azotobacter } \\
\left(10^{5} \text { CFU/100g }\right)\end{array}$ & $\begin{array}{c}\text { BPF } \\
\left(10^{6} \text { FU/100g }\right)\end{array}$ & $\begin{array}{c}\text { Bakteri }\left(10^{8}\right. \\
\text { CFU/100g })\end{array}$ \\
\hline Hortikultura & 1.02 & 1.35 & 1.01 & 1.23 & 1.25 \\
Pertanian Lahan Kering & 1.13 & 1.42 & 1.28 & 1.32 & 1.38 \\
Kebun Campuran & 1.11 & 1.32 & 1.09 & 1.30 & 1.25 \\
Hutan Lahan Kering & 0.66 & 1.39 & 0.99 & 1.25 & 1.40 \\
\hline
\end{tabular}

Penggunaan lahan untuk budidaya tanaman semusim dapat mendorong dinamika vegetasi yang semakin beragam. Selain itu adanya pengolahan pada sistem pertanian seperti pemupukan baik anorganik maupun organik ikut memacu pertumbuhan mikroba tanah. Hasil pengamatan ini didukung oleh Coleman et al. (2005) yang menyatakan bahwa biodiversitas tinggi dari mikroba terdapat pada tanah-tanah dengan vegetasi yang berbeda.

Hasil penelitian sejalan dengan Fitriatin $d k k$. (2006) yang menyatakan bahwa populasi bakteri pelarut fosfat serta aktivitas fosfatase lebih tinggi pada tanah dengan vegetasi tumpang sari antara jagung, kedelai dengan jati dibandingkan sistem monokultur hanya jagung atau kedelai. Tingginya populasi mikroba di tanah pertanian lahan kering ini diduga karena secara umum kandungan $\mathrm{C}$ organik pada tanah ini lebih tinggi ( $\mathrm{C}$ organik $12,57 \%)$. Kandungan $\mathrm{C}$ organik yang tinggi ini merupakan sumber energi dan nutrisi bagi pertumbuhan mikroba terutama mikroba yang heterotrof.

Hasil penelitian menunjukkan bahwa vegetasi hutan memiliki populasi mikroba yang lebih tinggi dibandingkan dengan vegetasi hortikultura, kebun campuran dan perkebunan. Hal ini dikarenakan vegetasi hutan memiliki karagaman yang tinggi serta karakteristik lahan yang memiliki bahan organik serta kelembaban yang lebih tinggi. Kondisi ini mendukung untuk pertumbuhan mikroba yang optimal. Ekosistem hutan merupakan suatu habitat yang memiliki keragaman hayati tinggi sehingga mendukung pertumbuhan mikroba yang tinggi (Pang dan Kolenko, 1986; Ramansyah dan Sudiana, 2004).

\subsection{Potensi Biodiversitas Mikroba Tanah}

Berdasarkan jumlah populasi mikroba tanah, Rao (1994) mengklasifikasikan tingkat populasi mikroba tanah ke dalam beberapa kelas. Semakin tinggi tingkat kelas, maka semakin tinggi potensi mikroba tanah tersebut dalam menunjang pertanian yang berkelanjutan. Jumlah mikroba tersebut menunjukkan tingkat aktivitasnya di dalam tanah. Semakin tinggi tingkat aktivitas mikroba, maka perannya dalam proses biokimia dalam tanah menjadi lebih besar sehingga penggunaan pupuk anorganik dapat dikurangi. Peran tersebut juga dipengaruhi oleh sifat tanah lainnya. Hasil pengamatan mikroba tanah pada berbagai tipe penggunaan lahan secara keseluruhan dihubungkan dengan sifat-sifat kimia dan fisika tanah menunjukan bahwa pertumbuhan populasi mikroba tanah dipengaruhi oleh sifat tanah lainnya.

Hasil klasifikasi jumlah populasi mikroba tanah di lokasi studi (Tabel 2) menunjukan bahwa potensi mikroba tanah ada pada kisaran rendah sampai dengan sangat tinggi. Potensi jamur di dalam tanah berada pada tingkat rendah $(48,28 \%)$ sampai dengan sedang (51,72\%). Potensi Azotobacter didominasi tingkat tinggi $(62,07 \%)$ sedangkan sisanya berada pada tingkat sedang $(37,93 \%)$. Potensi Actinomycetes di lokasi studi seluruhnya berada pada tingkat tinggi. Potensi mikroba tanah yang lebih tinggi terdapat pada jenis Bakteri Pelarut Fosfat (BPF), dimana 96,55\%, merupakan potensi sangat tinggi, dan sisanya $(3,45 \%)$ tingkat potensinya tinggi. Sedangkan potensi bakteri tanah yang sangat tinggi berada di seluruh areal tanah di lokasi studi. 
Tabel 2 Karakteristik potensi mikroba tanah di lokasi studi

\begin{tabular}{cccccc}
\hline \multirow{2}{*}{ Klasifikasi } & \multicolumn{5}{c}{ Persentase Jumlah Populasi Mikroba Tanah } \\
\cline { 2 - 5 } & Jamur & Actinomycetes & Azotobacter & BPF & Bakteri \\
\hline Sangat Rendah & - & - & - & - & - \\
Rendah & 48.28 & - & -37.93 & - & - \\
Sedang & 51.72 & - & 62.07 & 3.45 & 100.00 \\
Tinggi & - & 100.00 & - & 96.55 & - \\
Sangat Tinggi & - & - & &
\end{tabular}

Biodiversitas mikroba tanah ini merupakan potensi biofisik lahan yang dapat dimanfaatkan untuk pertanian yang berkelanjutan. Potensi mikroba tanah tersebut sangat penting diketahui berbagai pihak terkait dengan pemanfaatan lahan di KBU sehingga perlu diketahui sebarannya secara spasial di lokasi studi. Sebaran spasial ini dilakukan dengan bantuan SIG melalui proses spasial analysis dan geostatistical analysis data biofisik lahan di lokasi .

Berdasarkan klasifikasi berbagai jenis mikroba, penentuan potensi mikroba secara composit dinilai melalui bobot masing-masing potensi. Penilaian potensi mikroba tanah merupakan modifikasi penilaian produktivitas lahan berdasarkan Food and Agriculture Organization (1983) dengan memasukan nilai klasifikasi potensi beberapa jenis mikroba tanah yang dipertimbangkan. Bobot setiap tingkatan klasifikasi menunjukkan kontribusi potensinya secara aggregat di lapangan. Penilaian ini didasarkan pada pentingnya semua mikroba tanah yang dinilai terhadap produktivitas tanah dan tingkat potensinya digambarkan dalam bentuk klasifikasi Index Mikroba Tanah.

Hasil analisis menunjukkan potensi mikroba tanah secara composit bervariasi dari rendah hingga tinggi (Gambar 4). Seluas $5.020,23$ Ha $(34,64 \%)$ berpotensi tinggi, $2.309,86$ На $(15,94 \%)$ berpotensi sedang, dan seluas $2.362,76$ Ha $(16,30 \%)$ berpotensi rendah. Hal ini sejalan dengan hubungan antara mikroba tanah dengan jenis penggunaan lahan pada uraian sebelumnya, dimana lahan yang digunakan secara intensif untuk tanaman semusim cenderung mempunyai populasi mikroba tanah yang lebih tinggi dari yang lain.

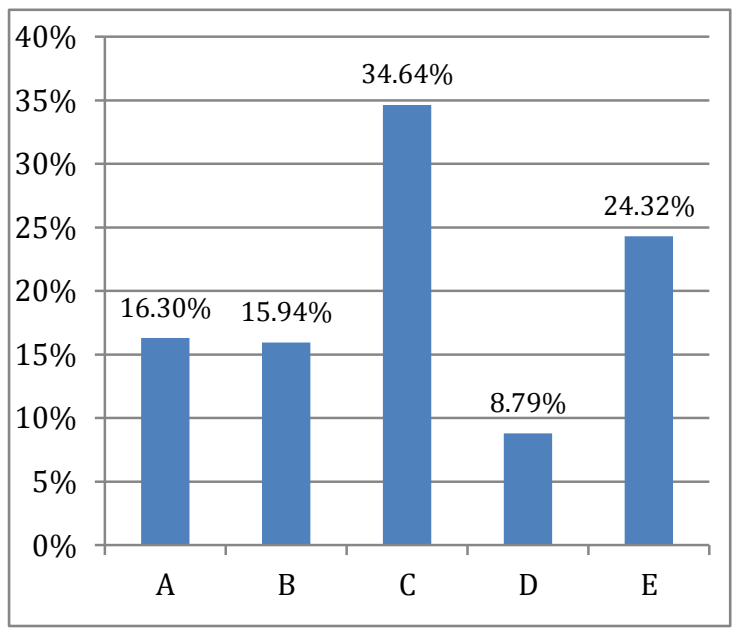

Keterangan : A : Potensi Rendah; B : Potensi Sedang; C: Potensi Tinggi; D: No Data; dan E : Pemukiman

\section{Gambar 4 Potensi Mikroba Tanah di Lokasi Studi}

Hasil ini selaras dengan Coleman et al. (2005) yang menyatakan bahwa biodiversitas tinggi dari mikroba terdapat pada tanah-tanah dengan vegetasi yang berbeda. Ini karena pemupukkan kompos dan kimiawi yang dilakukan petani setempat diberikan secara rutin dan intensif. Untuk mengetahui sebarannya secara spasial, potensi mikroba tanah di analisis melalui proses analisis spasial dan geostatistik dalam sistem informasi geografis. Sebarannya secara spasial dapat dilihat pada Gambar 5. 


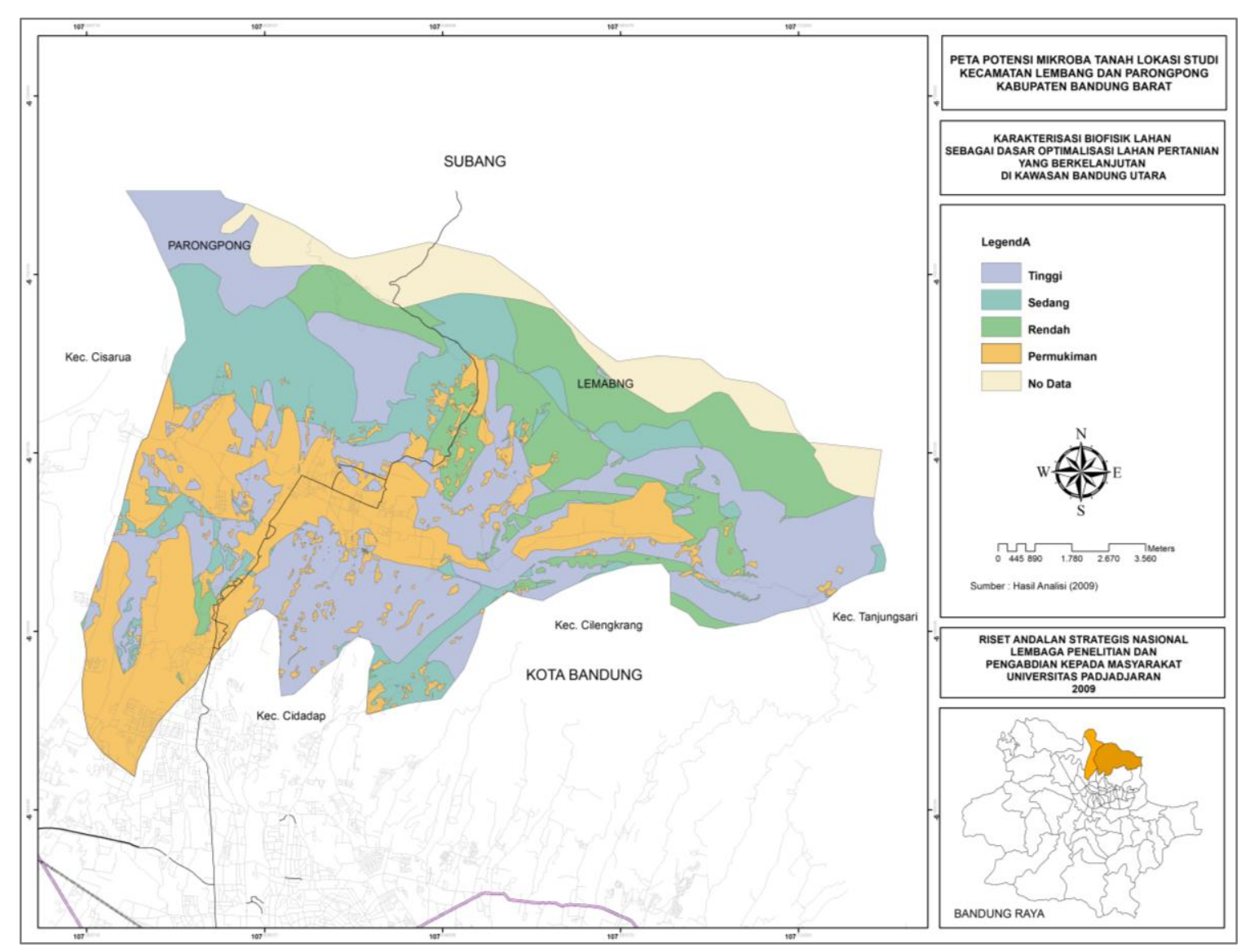

Gambar 5 Peta potensi mikroba tanah di lokasi studi

\section{KESIMPULAN}

Berdasarkan penelitian, potensi biofisik lahan di lokasi studi yang terletak di Kecamatan Lembang dan Parongpong Kabupaten Bandung Barat bervarasi dari satu satuan lahan dengan satuan lahan lainnya. Hal ini karenavariasi bentuk lahan, iklim, penggunaan lahan, dan bahan induk tanah sehingga menimbulkan variasi karakteristik biofisik lahan. Ini membutuhkan perhatian pemangku kepentingan di Kawasan Bandung Utara agar pemanfaatan lahan pertanian memperhatikan keragaman karakteristik.

Karakteristik biofisik lahan yang berpotensi di lokasi studi diuraikan berikut ini. Potensi biofisik lahan berdasarkan aspek biologi, terutama mikrobiologi tanah secara umum bervariasi dari rendah hingga tinggi.Terdapat lahan seluas 5.020,23 Ha (34,64\%) berpotensi tinggi, 2.309,86 Ha $(15,94 \%)$ berpotensi sedang, dan seluas $2.362,76$ Ha $(16,30 \%)$ berpotensi rendah.

\section{DAFTAR PUSTAKA}

Coleman, David C., William B. Whitmanb, Linking species richness, biodiversity and ecosystem function in soil systems. 2005. International Symposium on Impacts of Soil Biodiversity on Biogeochemical Rocesses in Ecosystems. Taipei, Taiwan. 2004. Pedobiologia 49 479-497.

Fitriatin, B.N. 2006. Analisis aktivitas fosfatase mikroba tanah dari rhizosfir tanaman pangan dan jati pada Ultisols. Laporan Penelitian. Jurusan Ilmu Tanah Fakultas Pertanian Universitas Padjadjaran.

Firtiatin, B.N., Joy, B. dan Subroto, T. 2007. Karakterisasi Aktivitas Fosfatase Mikroba Tanah dan Daya Katalisisnya terhadap Mineralisasi P Organik. Laporan Penelitian. Program Insentif Riset Dasar KMNRT. 
Food and Agriculture Organization of The United Nations, 1976. A Framework for Land Evaluation, Soil Bulletin 32, FAO, Rome, Italy.

Food and Agriculture Organization of The United Nations, 1983. A Guidelines : Land Evaluation for Rainfed Agriculture, Soil Bulletin 52, FAO, Rome, Italy.

Rao, S. 1994. Mikroorganisme Tanah Dan Pertumbuhan Tanaman. Ed 2. UIPress, Jakarta.

Saparatka, N. 2003. Phosphatase activities (ACP, ALP) in Agroecosystem Soils. Doctoral thesis. Swedish University of Agricultural Sciences. Uppsala. diss-

epsilon.slu.se/archive/00000286/0 1/Agraria_396_Docutech_Tryckfil [Diakses 15 Desember 2005]

Sitorus, Santun R. P., 2004, Evaluasi Sumberdaya Lahan, Penerbit Tarsito, Bandung. 